\title{
Toward Molecular Understanding of Polar Overdominance at the Ovine Callipyge Locus
}

\author{
M. Georges, ${ }^{*}$ C. Charlier, ${ }^{*}$ M. Smit, ${ }^{\dagger}$ E. Davis, ${ }^{*}$ T. Shay,${ }^{\dagger}$ X. Tordoir, ${ }^{*}$ H. Takeda, \\ F. CAIMENT, AND N. CocketT ${ }^{\dagger}$ \\ "Department of Genetics, Faculty of Veterinary Medicine, University of Liege (B43), 4000 Liege, Belgium; \\ ${ }^{\dagger}$ Department of Animal, Dairy and Veterinary Sciences, College of Agriculture, Utah State University, \\ Logan, Utah 84322-4700
}

The callipyge phenotype (Gk calli- beautiful + -pyge buttocks) is a generalized muscular hypertrophy described in sheep. It is due to an increase in the size and proportion of fast twitch muscle fibers. It manifests itself only after birth at $\sim 1$ month of age. It exhibits a rostrocaudal gradient being more pronounced in the muscle of the pelvic limb and torso, hence its name. It is accompanied by a decrease in all measures of fatness. Affected animals are characterized by an improved feed efficiency and dressing percentage (for review, see Cockett et al. 2001). Quite logically, the callipyge phenotype initially caught the attention of animal breeders because of its potential agronomic value. Ensuing studies, however, would reveal some remarkable features of the callipyge phenotype, especially its non-Mendelian mode of inheritance. These would quickly attract more attention among the scientific community than its potential economic value, especially since the quality of callipyge meat appeared to be mediocre!

The aim of this paper is to update and complement a recent review describing the present understanding of the genetics and epigenetics of the callipyge phenomenon (Georges et al. 2003).

\section{POLAR OVERDOMINANCE AT THE OVINE CLPG LOCUS}

The callipyge phenotype was first reported in the 1980 s, showing in $\sim 15 \%$ of offspring of a Dorset ram called "Solid Gold." When mated to wild-type ewes, callipyge rams descending from Solid Gold produced 50\% callipyge offspring, irrespective of sex. This Mendelian segregation ratio suggested that the callipyge phenotype results from an autosomal, nonrecessive mutation referred to as "CLPG" (Cockett et al. 1994). This monogenic hypothesis was confirmed when the $C L P G$ locus was mapped to a 4.5-cM marker interval on distal chromosome 18 (Cockett et al. 1994; Freking et al. 1998; Shay et al. 2001).

Unexpectedly, crosses involving callipyge ewes and wild-type rams did not produce any callipyge offspring, despite the transmission of the $C L P G$-carrying chromosome from the mothers to half their offspring. This nonequivalence of reciprocal crosses suggested the involvement of a gene undergoing parental imprinting that would only be expressed from the paternal allele. This hypothesis was supported by the observation that nonexpressing $C L P G^{M a t} /+{ }^{P a t}$ rams would transmit the callipyge phenotype to their $C L P G^{P a t}$-bearing offspring when mated to $+/+$ wild-type ewes. Parent-of-origin effects associated with uniparental disomies (UPDs) of the orthologous 14q32 region in man (pUPD14; MIM \#608149) and distal 12 region in the mouse (Georgiades et al. 2000) pointed toward the possible sharing of an imprinted locus in the three species.

However, matings performed subsequently between callipyge ewes and rams, each known to be of $+{ }^{\text {Mat }} / C L P G^{\text {Pat }}$ genotype, would not yield $50 \%$ callipyge offspring as expected in case of parental imprinting, but rather the unusual $75 \%$ wild-type versus $25 \%$ callipyge phenotypic ratio. Marker analysis indicated that only the ${ }^{\text {Mat }} / C L P G^{P a t}$ genotype was associated with the callipyge phenotype, the $C L P G^{\text {Mat }} / C L P G^{\text {Pat }}$ offspring being wild type although carrying the $C L P G$ mutation on their paternal chromosome. This non-Mendelian inheritance pattern was referred to as "polar overdominance" (Cockett et al. 1996). It was postulated to result either from a mutation that would switch the imprinting of the $C L P G$ gene from paternal to maternal expression, or would simultaneously knock out an imprinted paternally expressed trans-acting repressor and its target $C L P G$ gene. In the former case, the callipyge phenotype would result from the illegitimate absence of the $C L P G$ gene product, in the latter from its illegitimate presence. The latter model turns out to share many features with reality as we understand it today.

\section{THE CLPG MUTATION MAPS TO THE DLK1-GTL2-IMPRINTED DOMAIN}

A BAC contig spanning the $C L P G$ locus was constructed (Segers et al. 2000; Berghmans et al. 2001; Shay et al. 2001), and $\sim 500$ contiguous kilobases predicted to contain the mutation were sequenced (Charlier et al. $2001 \mathrm{~b}$ and unpubl.). In silico annotation of this sequence showed that the $C L P G$ mutation mapped to the newly described DLK1-GTL2-imprinted domain (Fig. 1).

This evolutionary conserved domain, which spans $\sim 1$ $\mathrm{Mb}$, harbors at least four protein-encoding genes with preferential expression from the paternal allele (BEGAIN, 
DLK1, PEG11, and DIO3), as well as multiple "long" (GTL2, anti-PEG11, MEG8, and MIRG) and "small" (C/D snoRNAs and miRNAs) noncoding RNA genes (ncRNA) with preferential expression from the maternal allele (Kobayashi et al. 2000; Miyoshi et al. 2000; Schmidt et al. 2000; Takada et al. 2000; Wylie et al. 2000; Charlier et al. 2001b; Paulsen et al. 2001; Cavaillé et al. 2002; Hernandez et al. 2002; Tsai et al. 2002; Yevtodiyenko et al. 2002; Seitz et al. 2003, 2004; M.A. Smit et al., in prep.).

BEGAIN (brain-enriched guanylate kinase-associated protein) encodes a protein that binds to the guanylate kinase domain of PSD-95/SAP90, a scaffolding protein at the postsynaptic cell membrane (Deguchi et al. 1998). It is widely expressed, producing multiple transcripts - as a result of alternative promoter usage and splicing-that exhibit paternal or biallelic expression in a tissue- and promoter-specific manner (M.A. Smit et al., in prep.). $D L K 1$ is a member of the EGF domain containing Notch/Delta/Serrate protein family whose function remains poorly understood. It has been implicated in adipogenesis, hematopoiesis, lymphopoeisis, and neuroendocrine differentiation, as well as tumorigenesis (Laborda 2000). Dlk1 null mice display accelerated adiposity, as well as symptoms shared with mUPD12 mice and mUPD14 humans: growth retardation, blepharophimosis, and skeletal abnormalities (Moon et al. 2002). A possible involvement of Dlkl in myogenesis is suggested by the myofiber hypertrophy and delayed maturation observed in murine pUPD12 fetuses expressing a double dose of $D l k l$ (Georgiadis et al. 2000), and by the known involvement of Notch signaling in myogenesis (see, e.g., Hirsinger et al. 2001; Conboy et al. 2003). PEG11 corresponds to a long ( $\sim 1300$ residues), uninterrupted open reading frame (ORF) that has the potential to code for a protein with a central portion that is highly similar to the gag and pol polyproteins of gypsy-like long terminal repeat (LTR) retrotransposons. It was shown to be hypermethylated in skeletal muscle as expected for a retroelement, yet is not flanked by sequences matching LTRs expected for such an element. The conservation of such a long ORF across mammals suggests that it fulfills an important function, yet, to the best of our knowledge, there is no evidence for its translation in any tissue so far. DIO3 codes for a type 3 iodothyronine deiodinase that degrades both T3 and T4 by catalyzing 5-deiodination of the inner ring, thereby contributing to the regulation of thyroid hormone levels in several tissues (St. Germain and Galton 1997).

The organization of the maternally expressed ncRNA genes remains more blurry. The first to be identified in a gene trap screen was GTL2, also known as MEG3 (Schuster-Gossler et al. 1996, 1998; Miyoshi et al. 2000). GTL2 is characterized by at least 12 exons and produces multiple transcripts by means of alternative splicing. The exon-intron organization is fairly well conserved across mammals, yet there is no evidence for a conserved ORF, suggesting that it is noncoding (see, e.g., Charlier et al. 2001b). MEG8 and MIRG were subsequently identified and characterized (Charlier et al. 2001b; Cavaillé et al. 2002; Seitz et al. 2004). They were shown to share a conserved exon-intron organization, extensive alternative splicing, and lack of conserved ORF with GTL2. Antisense $P E G 11$ transcripts expressed exclusively from the maternal allele were discovered as well (Charlier et al. 2001b). As all these supposedly ncRNAs are contiguous, expressed from the same strand and from the maternal allele, they might represent a single very long transcriptional unit akin to AIR (Lyle et al. 2000).

Interestingly, these "long" ncRNA genes are hosts for a multititude of "small" ncRNAs. Cavaillé et al. (2002) first identified tandem clusters of C/D snoRNA located in the introns of $M E G 8$ (also referred to as Rian), and-as their host gene- expressed exclusively from the maternal allele. It subsequently appeared that the same "long" ncRNAs might be hosting multiple miRNAs. By May 2004, 11 of the approximately 150 miRNAs known in human (e.g., the microRNA registry: http://www.sanger. ac.uk/Software/Rfam/mirna/index.shtml) mapped to the DLK1-GTL2 domain. Most of these would map to the introns of $M I R G$ or in the vicinity of PEG11. As a matter of fact, two, miR127 and miR136, mapped within the boundaries of the paternally expressed PEG11, making them the first miRNA genes in mammals with perfect complementarity to a potential target gene and raising the intriguing possibility of a mechanical link between imprinting and RNAi (Seitz et al. 2003). More recently, approximately $40 \mathrm{miRNAs}$ have been identified in the DLK1-GTL2 domain, most of them being part of tandem clusters located within the introns of MIRG (Seitz et al. 2004).

In the mouse, expression of the ncRNA genes and repression of the mRNA genes from the maternal allele has been shown to require a functional intergenic (located between $D L K 1$ and GTL2), germ-line-derived differentially methylated region $(I G-D M R)$, as transmission of the $\Delta$ $I G-D M R$ deletion causes a paternal epigenotype and modus operandi, while paternal transmission has no effect (Lin et al. 2003).

\section{THE CLPG MUTATION IS A POINT MUTATION AFFECTING A MUSCLE-SPECIFIC, LONG-RANGE cis-ACTING CONTROL ELEMENT}

We monitored the expression of the genes in the DLK1-GTL2 domain in a range of tissues and throughout development for sheep representing the four possible $C L P G$ genotypes. In none of the examined tissues and developmental stages was imprinting of any of the studied genes (DLK1, PEG11, BEGAIN, GTL2, antiPEG11, $M E G 8$, and $M I R G$ ) affected by CLPG genotype: mRNAs were always preferentially expressed from the paternal allele, while ncRNA genes were always preferentially expressed from the maternal allele (Charlier et al. 2001a; M.A. Smit et al., in prep. and unpubl.). Thus, this allowed us to exclude the first model for polar overdominance assuming a switch in imprinting of the CLPG gene from paternal to maternal expression.

However, the expression levels in skeletal muscle of a cluster of centrally positioned genes (DLK1, PEG11, GTL2, antiPEG11, MEG8, and MIRG, but not BEGAIN 

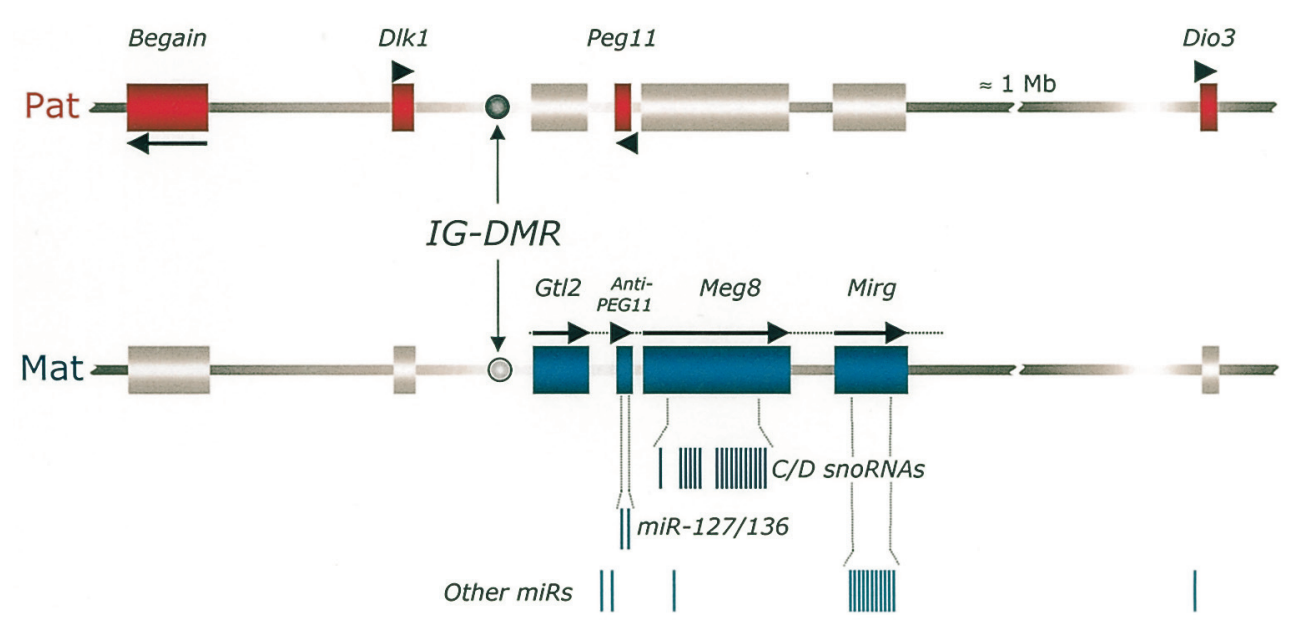

Figure 1. Schematic representation of the imprinted DLK1-GTL2 domain. The genes shown in red are protein-encoding genes that are preferentially transcribed from the paternal allele (Pat) in the directions indicated by the arrows. The genes shown in blue are noncoding RNA genes that are preferentially transcribed from the maternal allele (Mat) in the direction shown by the arrow. The C/D snoRNAs and miRNAs hosted, respectively, by MEG8, antiPEG11, and MIRG are shown underneath. The IG-DMR is an imprinting control element that is methylated (open circle) and inactive on the paternal allele, while unmethylated (closed circle) and active on the maternal chromosome, thereby leading to the expression of the ncRNA genes and silencing of the protein-encoding genes.

and DIO3) were clearly influenced by the $C L P G$ genotype (Charlier et al. 2001a; M.A. Smit et al., in prep. and unpubl.). More specifically, the concentrations of mRNA (DLK1, PEG11) were markedly increased in the two genotypes sharing the $C L P G$ mutation on their paternally inherited chromosome $\left(+^{\text {Mat }} / C L P G^{\text {Pat }}\right.$ and $C L P G^{\text {Mat }}$ ) $C L P G^{P a t}$ ), while the concentrations of ncRNA (GTL2, antiPEG11, MEG8, and $M I R G$ ) were markedly increased in the two genotypes sharing the $C L P G$ mutation on their maternally inherited chromosome $\left(C L P G^{\text {Mat }} /+^{\text {Pat }}\right.$ and $\left.+^{\mathrm{Mat}} /+^{\mathrm{Pat}}\right)$. The effect was limited to skeletal muscle. The easiest interpretation of these findings is that the $C L P G$ mutation affects a muscle-specific cis-acting regulatory element that controls the expression level of a subset of genes in the DLK1-GTL2 imprinted domain.

It is worthwhile noting that the $D L K 1$ and especially PEG11 mRNA levels were higher in skeletal muscle of $+{ }^{\text {Mat }} / C L P G^{\text {Pat }}$ when compared to $C L P G^{\text {Mat }} / C L P G^{P a t}$ individuals, while the ncRNA levels were higher in skeletal muscle of $C L P G^{\text {Mat }} / C L P G^{\text {Pat }}$ when compared to $C L P G^{\text {Mat }}+{ }^{\text {Pat }}$ individuals (Charlier et al. 2001a).

Having demonstrated the physical integrity of the locus for the CLPG allele by chromosome combing (absence of gross deletions or inversions; C. Charlier et al., unpubl.), we and others resequenced $>200 \mathrm{~Kb}$ encompassing the DLK1, GTL2, PEG11, antiPEG11, and MEG8 genes in order to identify the predicted cis-acting element and $C L P G$ mutation in it. To minimize confusion from neutral background mutations, both groups selected a wild-type and a $C L P G$ chromosome coalescing very recently for resequencing. This was achieved by selecting callipyge animals (therefore heterozygous $+{ }^{\text {Mat }} / C L P G^{\text {Pat }}$ ) that were homozygous for all known polymorphisms within and in the vicinity of the $C L P G$ locus. Three hundred and twenty polymorphisms were identified differentiating the resequenced + and CLPG alleles from the reference BAC sequence. The resequenced alleles, on the contrary, were identical over their entire length with the exception of a single A (+ allele) to $\mathrm{G}(C L P G$ allele) transition located between the $D L K 1$ and GTL2 genes, at $32.8 \mathrm{~Kb}$ from the closest genes, i.e., GTL2 (Freking et al. 2002; Smit et al. 2003).

Was this the $C L P G$ mutation? A number of arguments strongly support this conjecture. First, the A to G transition affects the third base pair of a dodecamer motif that is perfectly conserved in the 13 mammalian species in which it has been sequenced. The extensive conservation of this motif strongly suggests that it fulfills an important function. The dodecamer motif is itself embedded in a 2$\mathrm{Kb}$ segment exhibiting $>70 \%$ similarity between human and sheep. Second, the G allele was only encountered in the callipyge flock, i.e., descendents of Solid Gold, despite the screening of more than 270 animals representing 13 distinct breeds, including wild-type Dorset. Third, and most convincingly, Solid Gold was shown to be mosaic $(\mathrm{A} / \mathrm{A}+\mathrm{G})$, the $\mathrm{G}$ alleles representing $\sim 20 \%$ of the residues in its leucocyte DNA (Smit et al. 2003). The observation that only $15 \%$ of the approximately 150 offspring sired by Solid Gold were callipyge is in agreement with the ram being germ-line mosaic as well. This strongly suggests that the A to G transition occurred during Solid Gold's early development and virtually proves that it is the causative mutation. To provide final proof of its causality, we are generating transgenic mice with the corresponding nucleotide substitution by gene targeting and hope to recapitulate the callipyge phenotype and mode of inheritance in this more tractable model.

How might this putative cis-acting element operate? So far, classical approaches for the functional analysis of regulatory elements have provided relatively little insight. An 500-bp fragment encompassing the wild-type or mutant dodecamer motif in its center does not seem to affect the expression level of a luciferase reporter gene driven either by the $C M V$ or $I G F 2 \mathrm{P} 3$ promotor in $\mathrm{C} 2 \mathrm{C} 12$ 
myoblast cells (C. Charlier et al., unpubl.). Freking et al. (2002) indicated that the CLPG mutation lies at the end of a putative 10-bp MyoD binding motif and presented experimental evidence supporting binding to the $M y o D / E 47$ transcription factor. However, the 10-bp motif is not well conserved and the CLPG mutation does not seem to affect binding. We have obtained preliminary evidence from gel retardation experiments that an oligonucleotide encompassing the dodecamer motif binds a nuclear factor present in skeletal muscle, and that the CLPG mutation decreases the affinity for this factor (M.A. Smit et al., unpubl.). DNase hypersensitivity experiments are also underway (H. Takeda et al., unpubl.).

Intriguingly, Freking et al. (2002) identified a rare, unspliced transcript ("CLPG1") by random oligoprimed reverse transcriptase polymerase chain reaction (RT-PCR) from fetal skeletal muscle RNA, suggesting that the region encompassing the CLPG mutation might be transcribed. We have now extended this work and show that in skeletal muscle of 8-week-old animals, transcripts encompassing the mutation are produced from both strands, albeit exclusively from the CLPG allele (H. Takeda et al., unpubl.). It is unknown at this point whether this is a consequence or a cause of the more open chromatin configuration in the region. Note that a region encompassing the mutation and including $11 \mathrm{CpG}$ dinucleotides was shown by bisulfite sequencing to be generally more methylated on the + than on the CLPG allele, but that there was no simple correlation between allelic state and methylation for any of the examined sites (M.A. Smit et al., unpubl.).

\section{ECTOPIC EXPRESSION OF DLK1 PROTEIN IN SKELETAL MUSCLE OF $+^{\text {Mat }} /$ CLPG $^{\text {Pat }}$ INDIVIDUALS CAUSES THE CALLIPYGE PHENOTYPE}

The observed effect of the CLPG mutation on transcript levels of neighboring genes in skeletal muscle did not satisfactorily explain why only $+{ }^{M a t} / C L P G^{P a t}$ individuals express the callipyge phenotype. Indeed, ${ }^{\text {Mat }} / C L P G^{\text {Pat }}$ individuals share the overexpression of the $D L K 1$ and $P E G 11$ transcripts with $C L P G^{\text {Mat }} / C L P G^{\text {Pat }}$ individuals and the lack of overexpression of GTL2, antiPEG11, MEG8, and MIRG with $+{ }^{\text {Mat }} /+^{\text {Pat }}$ individuals, neither of which exhibits callipyge features. It is thus the combination of mRNA overexpression and lack of ncRNA overexpression that seems unique.

To gain a better understanding of why this might be, we monitored the expression of DLK1 at the protein level by immunochemistry (Davis et al. 2004). DLK1 protein could not be detected in skeletal muscle of $+{ }^{\mathrm{Mat}} /+^{\mathrm{Pat}}$, $C L P G^{M a t} /+^{P a t}$, and $C L P G^{M a t} / C L P G^{P a t}$ individuals, irrespective of muscle group and developmental stage. Remarkably, in $+{ }^{M a t} / C L P G^{\text {Pat }}$ individuals, DLK1 protein was found abundantly, albeit exclusively, in skeletal muscle exhibiting the muscular hypertrophy, e.g., Longissimus dorsi after 1 month of age. At earlier developmental stages or in nonhypertrophied muscle groups, DLK1 protein could not be detected in $+^{M a t} / C L P G^{\text {Pat }}$ individuals either. We thus observed a perfect association between the expression of DLK1 protein in skeletal mus- cle and their hypertrophy, both when differentiating individuals by $C L P G$ genotype and when distinguishing muscle groups within $+{ }^{M a t} / C L P G^{P a t}$ individuals.

To test whether this association might be causal, we generated transgenic mice expressing the membranebound form of the DLK1 protein (as we demonstrated that the corresponding $D L K 1$ transcripts are by far the most abundant in skeletal muscle of callipyge animals) in skeletal muscle under the dependence of a myosin light chain promoter and enhancer (Davis et al. 2004). The two transgenic lines that were produced indeed exhibited a muscular hypertrophy as a result of an increase in myofiber diameter. This strongly suggests that the ectopic expression of DLK1 protein that is observed in hypertrophied muscle of callipyge sheep causes this hypertrophy or at least contributes to it. We are presently using the same transgenic based approach to test the putative effect on muscle mass of ectopic expression of PEG11.

\section{POLAR OVERDOMINANCE SUPPORTS THE trans-INTERACTION BETWEEN THE PRODUCTS OF RECIPROCALLY IMPRINTED GENES}

The question remains why DLK1 protein is detected in skeletal muscle of ${ }^{\mathrm{Mat}} / C L P G^{\text {Pat }}$ individuals but not in that of $C L P G^{M a t} / C L P G^{\text {Pat }}$ animals, while DLK1 mRNA is present at comparable concentrations in skeletal muscle of both genotypes, transcribed from the paternal CLPG allele. Obviously the difference between the two genotypes is the maternal allele that is wild type and essentially silent in skeletal muscle of $+^{\mathrm{Mat}} / C L P G^{\text {Pat }}$ individuals while being $C L P G$ and thus producing ncRNA in skeletal muscle of $C L P G^{M a t} / C L P G^{\text {Pat }}$ animals. This thus suggests that in $C L P G^{M a t} / C L P G^{\text {Pat }}$ animals, the ncRNAs are blocking the translation of the $D L K 1 \mathrm{mRNAs}$ in trans explaining the absence of DLK1 protein (Fig. 2).

It is particularly interesting in this regard that the DLK1-GTL2 locus is remarkably rich in miRNA genes (cf. above). Could it be that one or several of these maternally expressed miRNAs target $D L K 1$ transcripts, thus mediating the translational trans inhibition postulated to underlie polar overdominance? To test this hypothesis we compared the affinity of 43 miRNAs predicted by Mirscan (Lim et al. 2003) in the DLK1-GTL2 domain using the human, murine, and rat sequence for the corresponding 3'UTR of DLK1 (X. Tordoir et al., unpubl.). Targetscan was used to quantify the affinity of the miRNAs for their target (Lewis et al. 2003), and affinities were summed across species. As the boundaries of the miRNAs cannot be determined unambiguously, multiple candidate miRNAs were actually tested for each primiRNA. The affinity of the predicted miRNAs for the 3'UTR of DLK1 was compared with their affinity for a set of 676 size-matched control 3'UTRs. The affinity of the miRNAs was either tested as a group (combinatorial rheostat hypothesis; Bartel 2004) or individually (individual rheostat hypothesis). We found no evidence supporting the fact that, as a group, the miRNAs predicted in the DLK1-GTL2 have a higher affinity for the 3'UTR of $D L K 1$ than for the 3'UTRs of a random set of control 


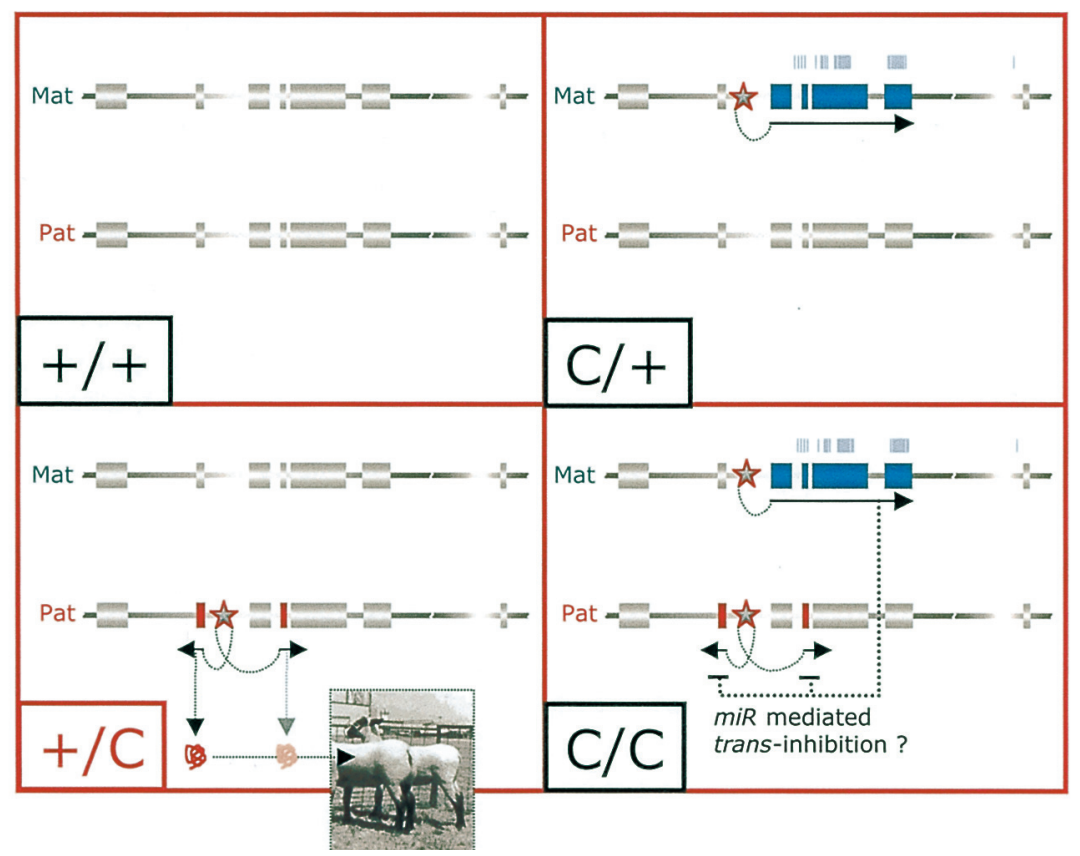

Figure 2. Schematic representation of the expression status of the genes in the DLK1-GTL2 imprinted domain in skeletal muscle of 8 -week-old sheep representing the four possible callipyge genotypes: $+/+, \mathrm{C} /+,+/ \mathrm{C}$, and $\mathrm{C} / \mathrm{C}$ (maternal allele/paternal allele). Only the $+/ \mathrm{C}$ animals express the phenotype and are therefore labeled $r e d$. The star represents the CLPG mutation, which enhances the expression of a core group of genes (DLK1, GTL2, PEG11, antiPEG11, MEG8, MIRG, C/D snoRNAs, miRNAs) in cis (dotted lines and arrows) without altering their imprinting status. Only in callipyge $(+/ \mathrm{C})$ animals is DLK1 (and possibly PEG11) protein detected in skeletal muscle causing the phenotype. The absence of DLK1 (and possibly PEG11) protein in C/C animals is postulated to result from a trans-inhibition mediated by the noncoding RNA genes expressed from the maternal allele. At present, the best candidate mediators of this trans effect are the miRNA genes present in the DLK1-GTLK2 domain.

genes $(p=0.49)$. When tested individually, however, we found one miRNA that had an affinity for $D L K 1$ superior to $90 \%$ of the best affinities found with the miRNA set for the 3'UTR of the control genes. Noteworthy, this miRNA also obtained the highest Mirscan score (19). The potential interaction between this miRNA and DLK1 transcripts is being tested experimentally.

It is noteworthy that there is strong evidence for a trans interaction between the maternally expressed $m i R 127$ and miR136 miRNA genes embedded in antiPEG11 and the perfectly complementary paternally PEG11 transcripts. First, Lin et al. (2003) provided indirect evidence by showing that concentrations of PEG11 transcripts were sixfold rather than twofold higher in mice inheriting the $\Delta$-IG-DMR deletion on their maternal chromosome when compared to wild-type controls. This is postulated to be due to the absence of miR127 and miR136 expression in the former. More directly, we have recently cloned PEG11 cleavage products from skeletal muscle of $C L P G^{\text {Mat }} / C L P G^{\text {Pat }}$ sheep predicted to result from the action of miR127 (E. Davis et al., in prep.). This observation is in perfect agreement with the lower levels of PEG11 transcripts observed in $C L P G^{\text {Mat }} / C L P G^{\text {Pat }}$ when compared to $+{ }^{\mathrm{Mat}} / C L P G^{\mathrm{Pat}}$ animals.

Although miRNAs are the most attractive candidate mediators of the postulated trans effect, alternative hypotheses should not be overlooked. It is intriguing in this regard that noncoding $H 19$ transcripts might bind to the same IMP (IGF2 mRNA binding protein) postulated to regulate translatability of some $I G F 2$ mRNAs (Runge et al. 2000). Might this point to a translational trans regulation of $I G F 2$ mediated by H19 ncRNA? Might similar mechanisms operate at the DLK1-GTL2 domain?

\section{CONCLUSIONS}

The study of the callipyge phenomenon has provided some unique opportunities to probe the novel epigenetic mechanisms that underlie its unusual mode of inheritance-polar overdominance. More than being just an ovine idiosyncrasy, the study of polar overdominance is likely to shed light on molecular mechanisms that might be involved in the inheritance of other phenotypes, including complex inherited disorders in the human. The study of the callipyge phenotype once again illustrates the potential value of domestic animal biodiversity in unraveling fundamental biological processes (Andersson and Georges 2004).

\section{ACKNOWLEDGMENTS}

This work was supported by grants from (i) the FRFC (no. 2.4525.96), (ii) Crédit aux Chercheurs (no. 1.5.134.00) from the FNRS, (iii) Crédit à la Recherche from the ULg, (iv) the SSTC (no. 0135), (v) the European Union (Callimir), (vi) the Utah Center of Excellence Program, (vii) the USDA/NRICGP (Grants \#94-04358, \#9635205 , and \#98-03455), and (viii) the Utah Agricultural 
Experiment Station, USU. Erica Davis is a fellow of the Belgian American Educational Foundation. Carole Charlier is Chercheur Qualifié from the FNRS. We are grateful to Anne Ferguson-Smith and Jérôme Cavaillé for sharing some of their results prior to publication.

\section{REFERENCES}

Andersson L. and Georges M. 2004. Domestic animal genomics: Deciphering the genetics of complex traits. Nat. Rev. Genet. 5: 202.

Bartel D.P. 2004. MicroRNAs: Genomics, biogenesis, mechanism, and function. Cell 116: 281.

Berghmans S., Segers K., Shay T., Georges M., Cockett N.E., and Charlier C. 2000. Breakpoint mapping positions the callipyge gene within a 285 kilobase chromosome segment containing the Gtl-2 gene. Mamm. Genome 12: 183.

Cavaillé J., Seitz H., Paulsen M., Ferguson-Smith A.C., and Bachellerie J.-P. 2002. Identification of tandemly-repeated C/D snoRNA genes at the imprinted human $14 \mathrm{q} 32$ domain reminiscent of those at the Prader-Willi/Angelman syndrome region. Hum. Mol. Genet. 11: 1527.

Charlier C., Segers K., Karim L., Shay T., Gyapay G., Cockett N., and Georges M. 2001a. The callipyge (CLPG) mutation enhances the expression of the coregulated DLK1, GTL2, $P E G 11$ and MEG8 genes in cis without affecting their imprinting status. Nat. Genet. 27: 367.

Charlier C., Segers K., Wagenaar D., Karim L., Berghmans S., Jaillon O., Shay T., Weissenbach J., Cockett N., Gyapay G., and Georges M. 2001b. Human-ovine comparative sequencing of a 250 kilobase imprinted domain encompassing the callipyge $(\mathrm{clpg})$ gene and identification of six imprinted transcripts: DLK1, DAT, GTL2, PEG11, antiPEG11 and MEG8. Genome Res. 11: 850.

Cockett N.E., Shay T.L., and Smit M. 2001. Analysis of the sheep genome. Physiol. Genomics 7: 69.

Cockett N.E., Jackson S.P., Shay T.L., Nielsen D., Green R.D., and Georges M. 1994. Chromosomal localisation of the callipyge gene in sheep (Ovis aries) using bovine DNA markers. Proc. Natl. Acad. Sci. 91: 3019.

Cockett N.Y., Jackson S.P., Shay T.L., Famir F., Berghmans S., Snowder G.D., Nielsen D.M., and Georges M. 1996. Polar overdominance at the ovine callipyge locus. Science 273: 236.

Conboy I.M., Conboy M.J., Smythe G.M., and Rando T.A. 2003. Notch-mediated restoration of regenerative potential to aged muscle. Science 302: 1575.

Davis E., Jensen C.H., Schroder H.D., Farnir F., Shay-Hadfield T., Kliem A., Cockett N., Georges M., and Charlier C. 2004. Ectopic expression of DLK1 protein in skeletal muscle of padumnal heterozygotes causes the callipyge phenotype. Curr. Biol. 14: 1858.

Deguchi M., Hata Y., Takeuchi M., Ide N., Hirao K., Yao I., Irie M., Toyoda A., and Takai Y. 1998. BEGAIN (brain-enriched gyanylate kinase-associated protein), a novel neuronal PSD95/SAP90-binding protein. J. Biol. Chem. 273: 26269.

Freking B.A., Keele J.W., Beattie C.W., Kappes S.M., Smith T.P., Sonstegard T.S., Nielsen M.K., and Leymaster K.A. 1998. Evaluation of the ovine callipyge locus. I. Relative chromosomal position and gene action. J. Anim. Sci. 76: 2062.

Freking B.A., Murphy S.K., Wylie A.A., Rhodes S.J., Keele J.W., Leymaster K.A., Jirtle R.L., and Smith T.P. 2002. Identification of the single base change causing the callipyge muscle hypertrophy phenotype, the only known example of polar overdominance in mammals. Genome Res. 12: 1496.

Georges M., Charlier C., and Cockett N. 2003. The callipyge locus: Evidence for the trans interaction of reciprocally imprinted genes. Trends Genet. 19: 248.

Georgiades P., Watkins M., Surani M.A., and Ferguson-Smith A.C. 2000. Parental origin-specific developmental defects in mice with uniparental disomy for chromosome 12. Develop- ment 127: 4719.

Hernandez A., Fiering S., Martinez E., Galton V.A., and St. Germain D. 2002. The gene locus encoding iodothyronine deiodinase type 3 (Dio3) is imprinted in the fetus and expresses antisense transcripts. Endocrinology 143: 4483.

Hirsinger E., Malapert P., Dubrulle J., Delfini M.C., Duprez D., Henrique D., Ish-Horowicz D., and Pourquie O. 2001. Notch signalling acts in postmitotic avian myogenic cells to control MyoD activation. Development 128: 107.

Kobayashi S., Wagatsuma H., Ono R., Ichikawa H., Yamazaki M., Tashiro H., Aisaka K., Miyoshi N., Kohda T., Ogura A., Ohki M., Kaneko-Ishino T., and Ishino F. 2000. Mouse Peg9/Dlk1 and human PEG9/DLK1 are paternally expressed imprinted genes closely located to the maternally expressed imprinted genes: Mouse Meg3/Gtl2 and human MEG3. Genes Cells 5: 1029.

Laborda J. 2000. The role of epidermal growth factor-like protein DLK in cell differentiation. Histol. Histopathol. 15: 119.

Lewis B.P., Shih I., Jones-Rhoades M.W., and Bartel D.P. 2003. Prediction of mammalian microRNA targets. Cell 115: 787.

Lim L.P., Lau N.C., Weinstein E.G., Abdelhakim A., Yekta S., Rhoades M.W., Burge C.B., and Bartel D.P. 2003. The microRNAs of Caenorhabditis elegans. Genes Dev. 17: 991.

Lin S.-P., Youngson N., Takada S., Seitz H., Reik W., Paulsen M., Cavaillé J., and Ferguson-Smith A.C. 2003. Asymmetric regulation of imprinting on the maternal and paternal chromosomes at the Dlk1-Gtl2 imprinted cluster on mouse chromosome 12. Nat. Genet. 35: 97.

Lyle R., Watanabe D., te Vruchte D., Lerchner W., Smrzka O.W., Wutz A., Schageman J., Hahner L., Davies C., and Barlow D.P. 2000. The imprinted antisense RNA at the $I g f 2 r$ locus overlaps but does not imprint Mas1. Nat. Genet. 25: 19.

Miyoshi N., Wagatsuma H., Wakana S., Shiroishi T., Nomura M., Aisaka K., Kohda T., Surani M.A., Kaneko-Ishino T., and Ishino F. 2000. Identification of an imprinted gene, $M e g 3 / G t l 2$ and its human homologue $M E G 3$, first mapped on mouse distal chromosome 12 and human chromosome 14q. Genes Cells 5: 211.

Moon Y.S., Smas C.M., Lee K., Villena J.A., Kim K.H., Yun E.J., and Sul H.S. 2002. Mice lacking paternally expressed Pref-1/Dlk1 display growth retardation and accelerated adiposity. Mol. Cell. Biol. 22: 5585.

Paulsen M., Takada S., Youngson N.A., Benchaib M., Charlier C., Segers K., Georges M., and Ferguson-Smith A. 2001. Detailed sequence analysis of the imprinted Dlk1-Gtl2 locus in three mammalian species identifies highly conserved genomic elements and a domain structure different from the Igf2-H19 region. Genome Res. 11: 2085.

Runge S., Nielsen F.C., Nielsen J., Lykke-Andersen J., Weweri U.M., and Christiansen J. 2000. H19 RNA binds four molecules of insulin-like growth factor II mRNA-binding protein. J. Biol. Chem. 275: 29562.

Schmidt J.V., Matteson P.G., Jones B.K., Guan X.-J., and Tilghman S.M. 2000. The Dlkl and Gtl2 genes are linked and reciprocally imprinted. Genes Dev. 14: 1997.

Schuster-Gossler K., Bilinski P., Sado T., Ferguson-Smith A., and Gossler A. 1998. The mouse GTL2 gene is differentially expressed during embryonic development, encodes multiple alternatively spliced transcripts, and may act as an RNA. Dev. Dyn. 212: 214.

Schuster-Gossler K., Simon D., Guénet J.-L., Zachgo J., and Gossler A. 1996. GTL2lacz, an insertional mutation on mouse chromosome 12 with parental origin dependent phenotype. Mamm. Genome 7: 20.

Segers K., Vaiman D., Berghmans S., Shay T., Beever J., Cockett N., Georges M., and Charlier C. 2000. Construction and characterization of an ovine BAC contig spanning the callipyge locus. Anim. Genet. 31: 352.

Seitz H., Royo H., Bortolin M.-L., Lin S.-P., Ferguson-Smith A.C., and Cavaillé J. 2004. A large imprinted microRNA gene cluster at the mouse Dlk1-Gt12 domain. Genome Res. 14: 1741.

Seitz H., Youngson N., Lin S.-P., Dalbert S., Paulsen M., Bachellerie J.P., Ferguson-Smith A.C., and Cavaillé J. 2003. 
Imprinted microRNA genes transcribed antisense to a reciprocally imprinted retrotransposon-like gene. Nat. Genet. 34: 261.

Shay T.L., Berghmans S., Segers K., Meyers S., Beever J.E., Womack J.E., Georges M., Charlier C., and Cockett N.E. 2001. Fine mapping and construction of a bovine contig spanning the ovine callipyge locus. Mamm. Genome 12: 141.

Smit M., Segers K., Shay T., Baraldi F., Gyapay G., Snowder G., Georges M., Cockett N., and Charlier C. 2003. Mosaicism of Solid Gold supports the causality of a non-coding A to G transition in the determinism of the callipyge phenotype. Genetics 163: 453.

St. Germain D.L. and Galton V.A. 1997. The deiodinase family of selenoproteins. Thyroid 7: 655 .

Takada S., Tevendale M., Baker J., Georgiades P., Campbell E.,
Freeman T., Johnson M.H., Paulsen M., and Ferguson-Smith A.C. 2000. Delta-like and Gtl2 are reciprocally expressed, differentially methylated linked imprinted genes on mouse chromosome 12. Curr. Biol. 10: 1135.

Tsai C.-E., Lin S.-P., Ito M., Takagi N., Takada S., and Ferguson-Smith A.C. 2002. Genomic imprinting contributes to thyroid hormone metabolism in the mouse embryo. Curr. Biol. 12: 1221 .

Wylie A.A., Murphy S.K., Orton T.C., and Jirtle R.L. 2000. Novel imprinted $D L K 1 / G T L 2$ domain on human chromosome 14 contains motifs that mimic those implicated in IGF2/H19 regulation. Genome Res. 10: 1711.

Yevtodiyenko A., Carr M.S., Patel N., and Schmidt J.V. 2002. Analysis of candidate imprinted genes linked to Dlk1-Gt12 using a congenic mouse line. Mamm. Genome 13: 633. 


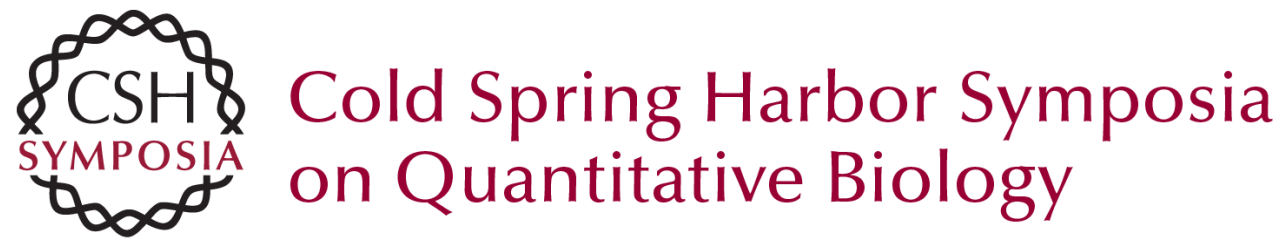

\section{Toward Molecular Understanding of Polar Overdominance at the Ovine Callipyge Locus}

M. GEORGES, C. CHARLIER, M. SMIT, et al.

Cold Spring Harb Symp Quant Biol 2004 69: 477-484

Access the most recent version at doi:10.1101/sqb.2004.69.477

References This article cites 41 articles, 16 of which can be accessed free at: http://symposium.cshlp.org/content/69/477.full.html\#ref-list-1

License

Email Alerting Receive free email alerts when new articles cite this article - sign up in Service the box at the top right corner of the article or click here. 